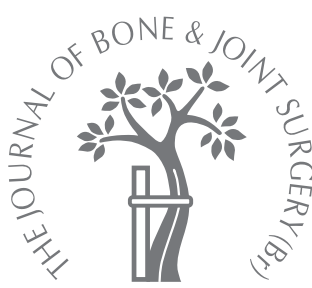

\title{
Results of the Birmingham Hip Resurfacing dysplasia component in severe acetabular insufficiency
}

\author{
A SIX- TO 9.6-YEAR FOLLOW-UP
}

D. J. W. McMinn, J. Daniel,

H. Ziaee,

C. Pradhan

From The McMinn

Centre, Birmingham, England
D. J. W. McMinn, FRCS, Consultant Orthopaedic Surgeon

J. Daniel, FRCS, Director of Research

H. Ziaee, BSc(Hons), Biomedical Scientist

C. Pradhan, FRCS, Staff

Orthopaedic Surgeon

The McMinn Centre, 25

Highfield Road, Edgbaston,

Birmingham B15 3DP, UK.

Correspondence should be sent to Mr J. Daniel; e-mail: josephdaniel@mcminncentre. co.uk

(c)2008 British Editorial Society of Bone and Joint Surgery doi:10.1302/0301-620X.90B6. $19875 \$ 2.00$

$J$ Bone Joint Surg [Br] 2008:90-B:715-23.

Received 28 June 2007;

Accepted after revision 14

January 2008

The dysplasia cup, which was devised as an adjunct to the Birmingham Hip Resurfacing system, has a hydroxyapatite-coated porous surface and two supplementary neutralisation screws to provide stable primary fixation, permit early weight-bearing, and allow incorporation of morcellised autograft without the need for structural bone grafting.

A total of 110 consecutive dysplasia resurfacing arthroplasties in 103 patients (55 men and 48 women) performed between 1997 and 2000 was reviewed with a minimum follow-up of six years. The mean age at operation was 47.2 years (21 to 62 ) and 104 hips (94\%) were Crowe grade II or III.

During the mean follow-up of 7.8 years (6 to 9.6$)$, three hips $(2.7 \%)$ were converted to a total hip replacement at a mean of 3.9 years ( 2 months to 8.1 years), giving a cumulative survival of $95.2 \%$ at nine years (95\% confidence interval 89 to 100$)$. The revisions were due to a fracture of the femoral neck, a collapse of the femoral head and a deep infection. There was no aseptic loosening or osteolysis of the acetabular component associated with either of the revisions performed for failure of the femoral component. No patient is awaiting a revision.

The median Oxford hip score in 98 patients with surviving hips at the final review was 13 and the 10th and the 90th percentiles were 12 and 23 , respectively.

Arthritis which develops in a hip with developmental dysplasia is a surgical challenge. The acetabulum is deficient in its shape and the quality of the bone of its roof is poor and does not favour adequate component fixation. Torsional deformities of the femur and discrepancies in leg length compound the problem. Multiple previous childhood operations can compromise the outcome. These patients are relatively young and wish to remain active, jeopardising the survival of any arthroplasty device. A destructive type of primary arthritis may also lead to subluxation of the hip and severe secondary acetabular insufficiency in a hitherto well-developed hip, necessitating complex acetabular reconstruction and stabilisation.

The need for supplementary stabilisation of the acetabular component and for bone grafting can be assessed in several ways. ${ }^{1,2}$ Proximal displacement of the femoral head, ${ }^{3}$ the extent and position of the false acetabulum ${ }^{4}$ and the percentage of the acetabular component which is uncovered, ${ }^{5}$ have all been used as rough guides. Strategies for acetabular stabilisation (Fig. 1) include controlled medialisation, ${ }^{6}$ proximal positioning of the hip centre, ${ }^{7}$ supplementary structural bone grafting with screw fixation, morcellised bone grafting with a metal mesh or re-inforcement rings, and different combinations of these techniques. ${ }^{2}$ Studies have shown that long-term survival is significantly worse if the centre of rotation of the hip is moved proximally or laterally. 8,9 Augmentation of the acetabulum with a bone graft from a femoral head has been proposed ${ }^{10,11}$ but has a high rate of failure in the long-term. ${ }^{12}$ Kobayashi et $\mathrm{al}^{13}$ showed excellent results with a combination of bone block grafting and proximal placement of the acetabular component in order to obtain cover of the most proximal point (apex) of the component by the ilium. However, in their opinion success with this procedure depends on selecting patients aged over 48 years with a natural acetabular cover of at least $50 \%$. In most cases of Crowe $\mathrm{e}^{3}$ grade I dysplasia and in some of Crowe II we have used the standard Birmingham Hip Resurfacing (BHR) acetabular component (Smith and Nephew Orthopaedics, Warwick, United Kingdom) when the bony acetabulum provides adequate cover for primary stability. However, in some instances of Crowe II dysplasia and occasionally in Crowe I, the bony acetabulum is very shallow and offers poor primary cover for the component. 


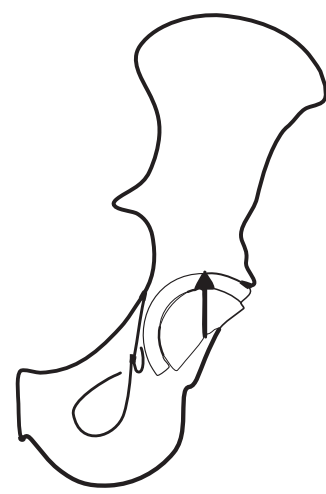

Fig. 1a

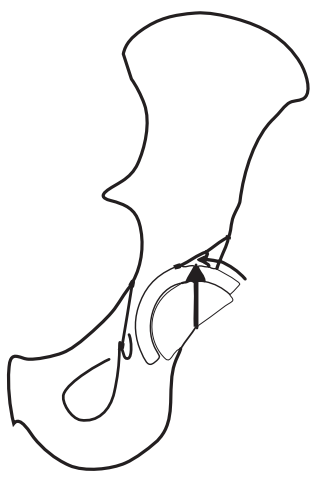

Fig. 1b

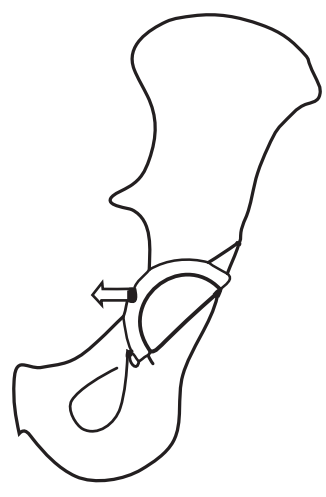

Fig. 1c

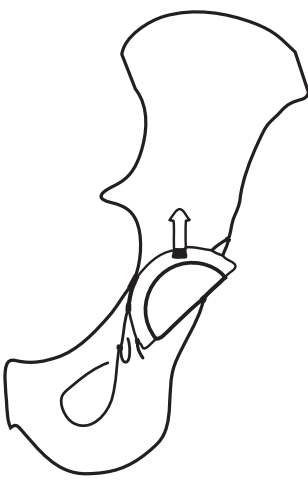

Fig. 1d

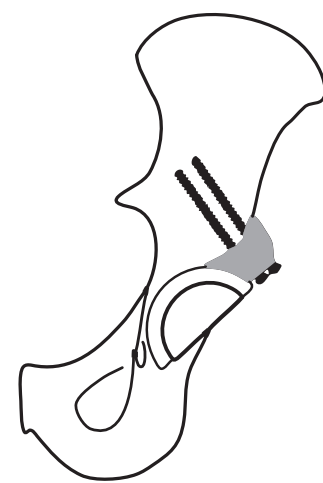

Fig. 1e

a) The normal acetabulum provides good fixation for a hemispherical acetabular component, with the apex of the implant (straight arrow), lying securely within the bony acetabulum. b) The dysplastic acetabulum is deficient superolaterally (curved arrow) and the apex of the component lies outside the region of bony support. c) Controlled medialisation, d) proximal shift of the hip centre and e) bone graft augmentation are some of the strategies classically described to overcome acetabular insufficiency.

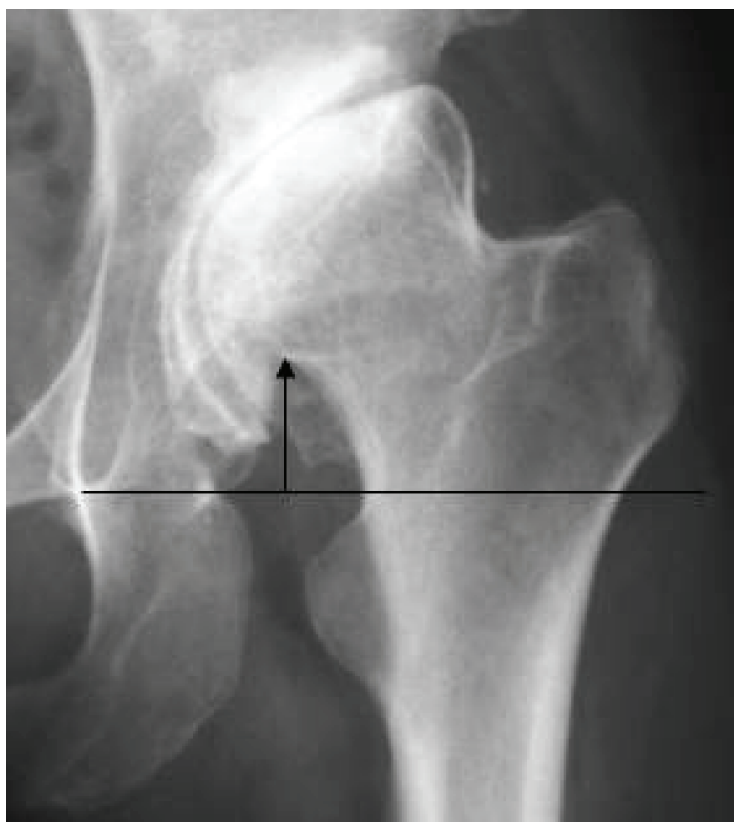

Fig. $2 a$

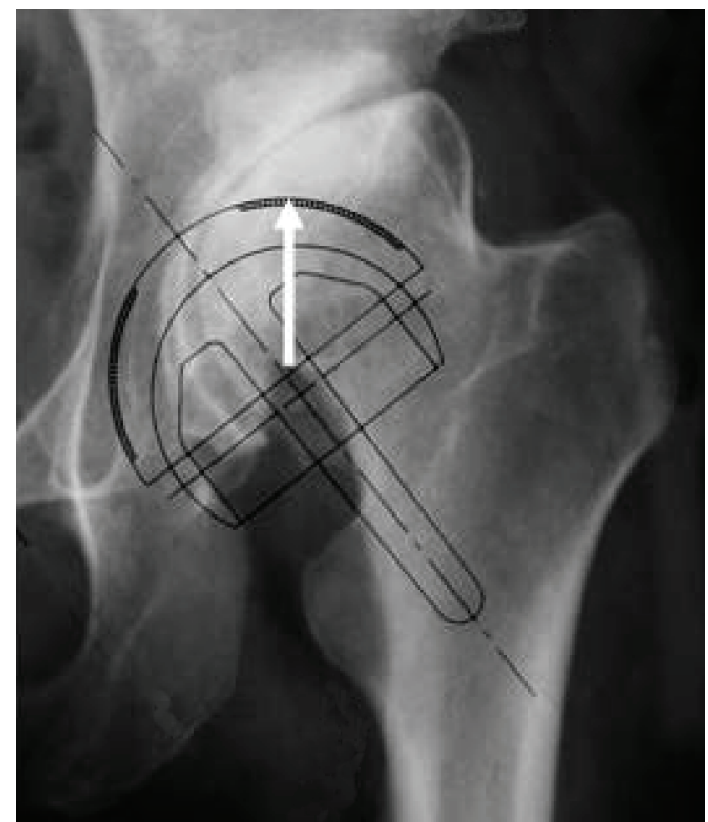

Fig. 2b

a) A radiograph of the hip showing severe arthritis secondary to developmental dysplasia in a 37-year-old woman. The proximal migration of the femoral head is $<50 \%$ of the width of the femoral head and $<10 \%$ of the pelvic height, and the dysplasia is therefore classified as Crowe I. b) Templating, however, shows that the apex of the acetabular component (white arrow) would lie outside the bony acetabular cover even after advancing the component medial to the true floor.

Unfortunately, most classifications, ${ }^{3,14,15}$ including the widely-used Crowe system, ${ }^{3}$ grade dysplasia on the basis of the proximal migration of the femoral head rather than on the shape and stability provided by the bony acetabulum. We have several cases to illustrate this point, one of which is shown in Figure 2. The measured proximal migration of the femoral head categorises it as Crowe grade I dysplasia, but the apex of the acetabular component lies outside the cover afforded by the acetabulum even after advancing the component medial to the true floor. It therefore needs supplementary fixation and augmentation by a bone graft. 

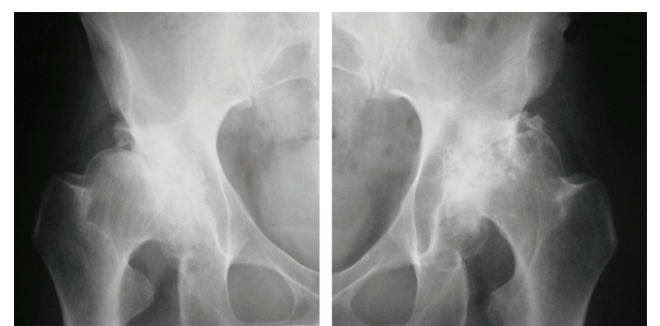

Fig. 3a

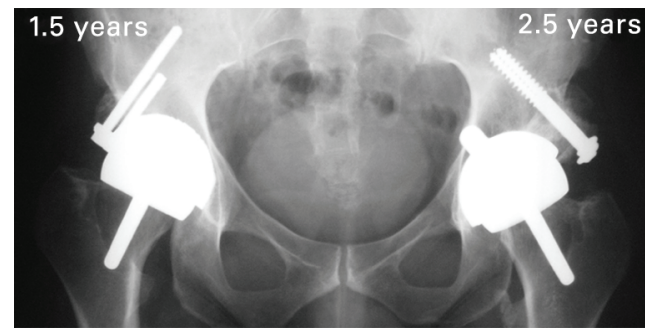

Fig. 3c
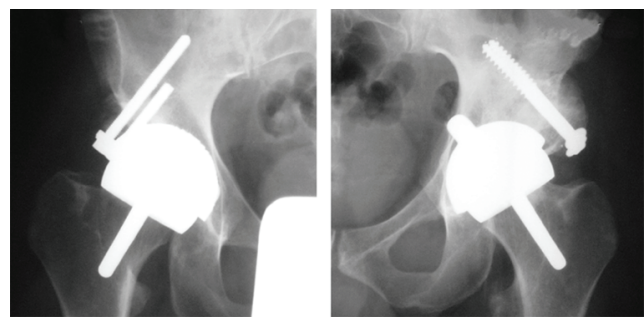

Fig. $3 b$

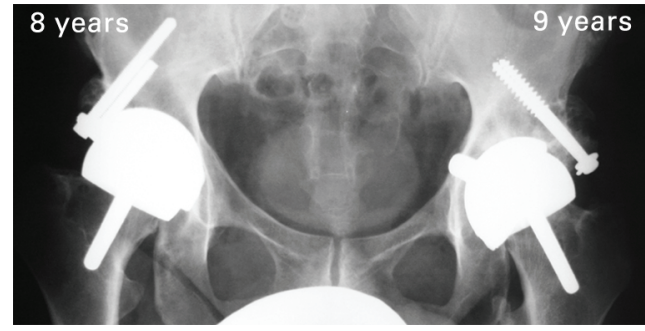

Fig. 3d

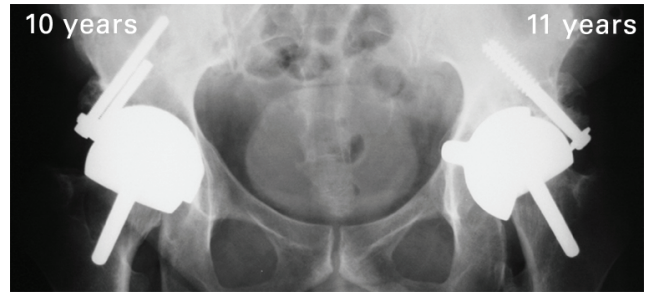

Fig. 3e

a) Radiographs of a 38-year-old man with bilateral dysplastic acetabula. When he developed severe arthritic changes on the left side, the dysplasia component and the Birmingham Hip Resurfacing were unavailable. He was treated with a McMinn hybrid resurfacing device with block bone graft and lag screw fixation to support the acetabular component. b) and c) Early follow-up radiographs show good component alignment and optimal bone graft apposition and fixation. A year later he developed arthritic changes of the contralateral hip, by which time a Birmingham Hip Resurfacing dysplasia component was available and was used with supplementary screws and morcellised bone graft. d) At the nine-year follow-up there were symptoms and radiological appearances of loosening on the left side. e) The ten-year review of the dysplasia component shows perfect hip function with excellent bone graft incorporation and acetabular remodelling and no evidence of loosening or migration. At the 11-year follow-up the acetabular component on the left has tilted into a vertical position and he is awaiting revision surgery.

It is unwise to think that because a particular case can be classified as Crowe grade I, the acetabular deficiency will always be minor and that a standard component will suffice. Resurfacing with a standard component in such a case would carry a high chance of early loosening.

It may be argued that in such a case augmentation can be provided with a structural bone graft using fixation with lag screws. We used this method before the development of the BHR and the availability of the dysplasia component (Fig. 3). Successive follow-up radiographs show the failure of the bone graft to osseointegrate, eventually leading to acetabular loosening. However, these earlier implants (McMinn Hybrid Components, Corin Medical Ltd, Cirencester, United Kingdom) were a different design from the BHR and did not have a beaded hydroxyapatite (HA)- coated surface but HA coating on a smooth surface. The extent to which this feature hastened the failure of the Corin device is unknown, but the failure of the block bone graft to osseointegrate is clear. We agree with previous authors $^{12,16}$ that although the early results with structural bone grafting are good, the long-term results are far from satisfactory.

In a conventional cemented total hip replacement (THR) primary stability can be improved with additional bone cement, and in a cementless acetabular component screw fixation can be used where bony support is available. Neither of these solutions is suitable for the severely-deficient acetabulum. With a resurfacing acetabular component, screw holes cannot be made in the floor of the component. Hence the dysplasia cup (Smith and Nephew Orthopaedics) (Fig. 4) 


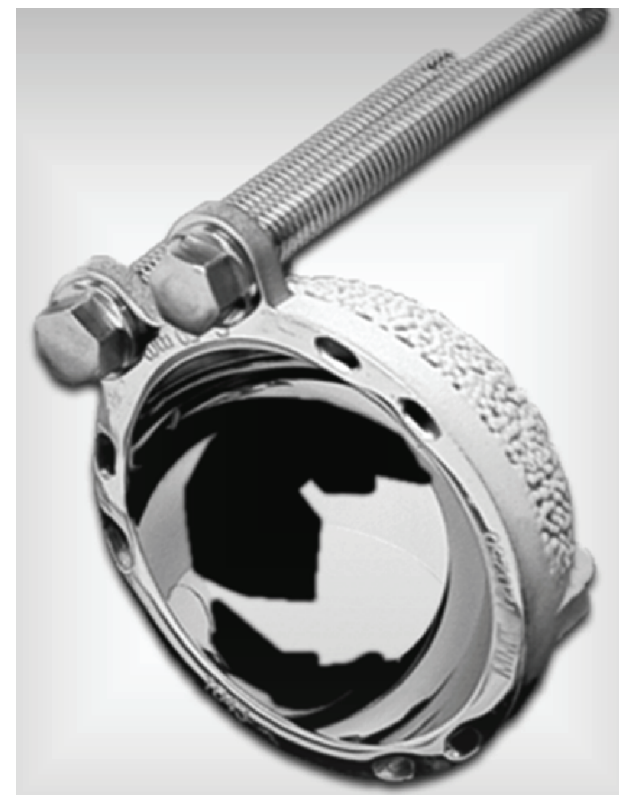

Fig. 4

The Birmingham hip resurfacing dysplasia component.

was produced as an adjunct to the BHR system. It articulates with a standard BHR femoral head component or its modular version on a stemmed THR, although the latter is not the subject of this report.

We have followed-up a consecutive series of dysplasia BHR procedures, carried out on hips with severe acetabular insufficiency. Less severe degrees of dysplasia were excluded from this group, as they were managed using a standard BHR acetabular component employing techniques such as medialisation or slight elevation of the centre of rotation of the hip.

\section{Patients and Methods}

The dysplasia BHR component, like the standard component, is uncemented with an HA-coated porous surface. In addition, it has two offset threaded lugs for supplementary fixation using neutralisation screws. The bony defect is then roughened and filled with morcellised bone autograft. The graft is held in position with Surgicel (Ethicon, Cornelia, Georgia) which is sutured into place. The screws obtain purchase in the sclerotic bone of the false acetabulum rather than in the osteopenic bone in the acetabular roof. The primary stability of this construct allows patients to bear weight from the first day after operation.

A consecutive series of 110 hips (103 patients) with severe acetabular insufficiency and end-stage arthritis, treated with a dysplasia BHR between 1997 and 2000, were assessed. All the operations were performed by the senior author (DJWM). There were 55 men (56 hips) and 48 women (54 hips). The mean age at operation was 47.2 years (21 to 62).
There were 45 women ( 51 of 54 hips) under the age of 55 years, and under the age of 50 years there were almost twice as many women (35 hips) as men (17 hips).

A total of 48 hips $(43.6 \%)$ were classified as Crowe grade III, $56(50.9 \%)$ as Crowe grade II and six (5.5\%) as Crowe grade I. Measurements of leg length were made radiologically. A total of 19 patients (20 hips) had one or more previous hip operation in childhood, including femoral and pelvic osteotomies with internal fixation.

The need to use a dysplasia component rather than the standard device was established on the basis of pre-operative templating (Fig. 2). If after medialising the acetabular component or by choosing a slightly raised hip centre with the template, a significant portion of the acetabular component was likely to remain uncovered, the possible need for a dysplasia component was registered. At operation the stability of the true acetabular component and the extent of the lateral uncovering were the deciding factors as to whether to use a standard or a dysplasia component. Using a depth gauge the uncovering was measured from the edge of the component to the margin of the available bony cover at the deepest point. The mean amount of uncovering was $18.5 \mathrm{~mm}$ (10 to 30$)$.

All procedures were performed through a posterior approach. Several critical surgical details merit emphasis. The size of component which can be inserted into the dysplastic acetabulum is governed by the anteroposterior dimension of the bony acetabulum. Care must be taken not to ream away the anterior acetabular wall, which is often hypoplastic. The successively larger reamers should be biased posteriorly, so that the thickened posterior acetabular wall is reamed and the thin anterior wall is preserved. The surgeon must carefully judge the largest size of reamer that can be safely used, and if that does not allow an acetabular component with a corresponding femoral head size to clear the femoral neck, then a THR must be performed. The median component size used was $56 \mathrm{~mm}$ (46 to 66).

After the acetabular component is positioned, as the first screw advances through the lug and reaches the prepared screw hole on the bony surface, further advancement has to progress slowly and with care, ensuring that the selftapping threads of the screw obtain purchase in the bone and advance with each turn. Failure to control this step will result in the acetabular component being disengaged from the pelvis as the screw advances. Once initial purchase has been obtained, the screw advances without difficulty and tightening it against the component towards the end securely locks the implant in place. Advancement of the second screw is not fraught with such risk as the component is already securely fixed (Fig. 5).

A few other precautions should be borne in mind when resurfacing dysplastic hips. Anteversion of the femoral neck is a frequent accompanying feature of dysplastic hips. The total femoral neck anteversion ${ }^{17}$ plus acetabular component anteversion should equal $45^{\circ}$. It is important that the surgeon measures femoral neck anteversion before embark- 


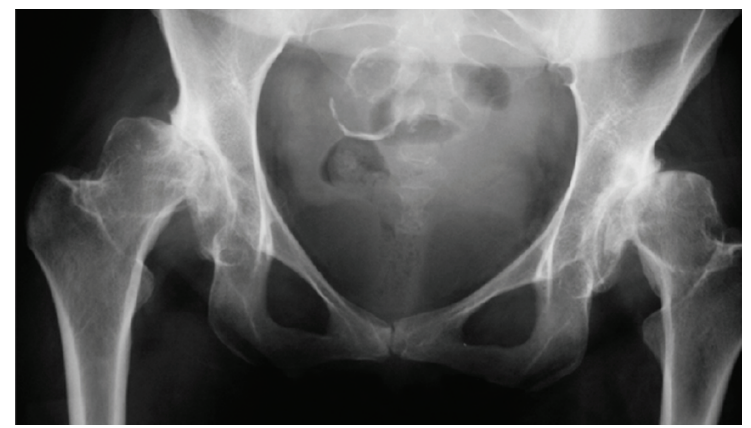

Fig. $5 a$

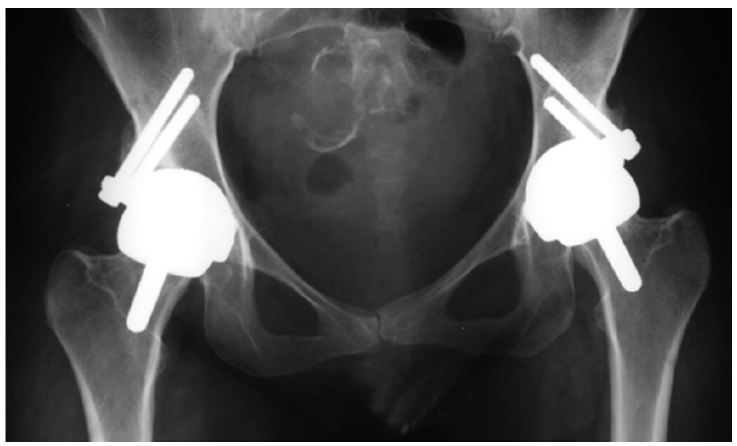

Fig. $5 c$

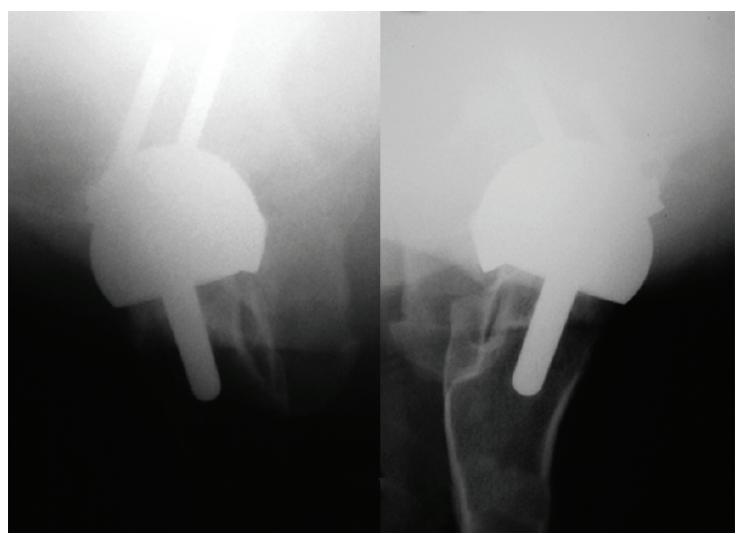

Fig. 5 e

ing on positioning of the acetabular component. Lesser degrees of excess femoral anteversion can be compensated for by implanting the acetabular component in a less anteverted position. However, if the anteversion of the femoral neck is in excess of $45^{\circ}$ a femoral derotation osteotomy is required if the patient is to be managed with hip resurfacing.

Although the senior author has performed nine procedures where a BHR was combined with simultaneous subtrochanteric derotation femoral osteotomy secured with an AO dynamic compression plate (Synthes GmbH, Solo-

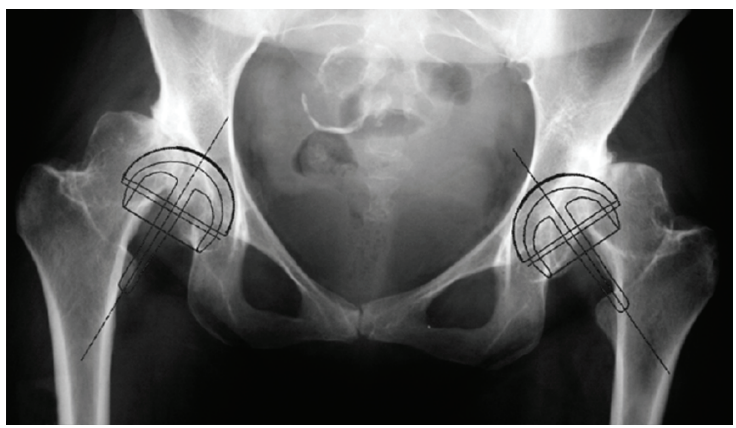

Fig. $5 b$

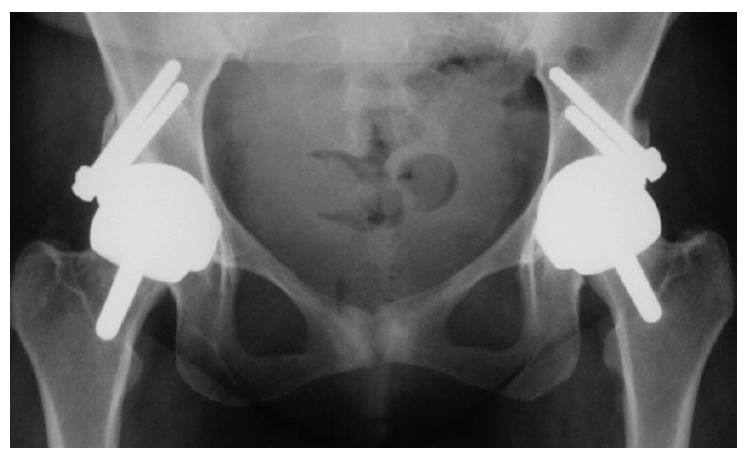

Fig. 5d

Radiographs of a 37-year-old woman with bilateral hip dysplasia and severe arthritis who a) presented with progressively worsening pain, severe restriction of hip movement, deteriorating hip function, and an awkward limp with apparent leg-length discrepancy. b) At operation the acetabular component uncovering was $18 \mathrm{~mm}$ on the left and $22 \mathrm{~mm}$ on the right. c) Bilaterally dysplasia Birmingham Hip Resurfacing components were used with morcellised autograft to reconstruct the insufficient socket. d) and e) At 6.5-years follow-up she reports excellent hip function and has no adverse radiological features.

thurn, Switzerland), only one of them (Fig. 6) has had a long enough follow-up to be included in this report.

Rehabilitation following a combined osteotomy/resurfacing operation is arduous and it is only a reasonable procedure in young, fit patients. In older patients a THR with correction of excess anteversion of the femoral neck is a better procedure. If excess anteversion is suspected it is preferable to determine this with a pre-operative CT scan, and to discuss carefully with the patient the pitfalls and benefits of resurfacing against THR. 


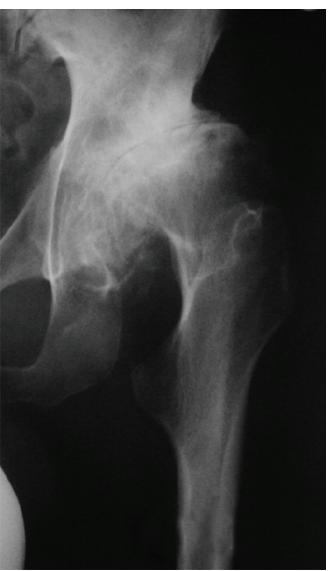

Fig. 6a

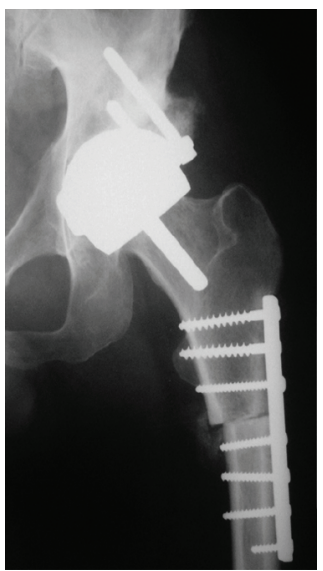

Fig. 6b

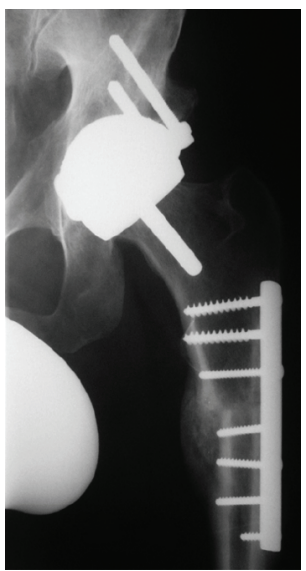

Fig. $6 \mathrm{c}$

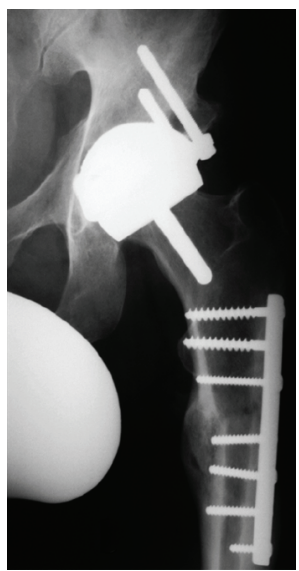

Fig. 6d

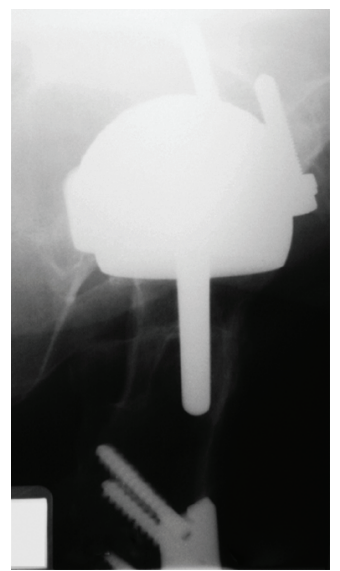

Fig. 6e

A 50 -year-old man with developmental dysplasia of the hip had $60^{\circ}$ of femoral neck anteversion and a coxa valga deformity. A subtrochanteric derotation osteotomy was performed secured with a seven-hole dynamic compression plate. At six-year follow-up, he reports normal hip function and regularly plays tennis.

The patients remained in hospital for a maximum of six nights after the operation. None needed outpatient physiotherapy after discharge. The peri-operative antibiotic prophylaxis and thromboprophylaxis measures used were the same as in our general series. ${ }^{18}$

Only after a femoral osteotomy was any patient restricted to non-weight-bearing. All started mobilising on the first day after operation using elbow crutches. In total $55 \%$ of patients (61 hips) were allowed to bear weight fully starting on the first day. In $45 \%$ of patients ( 49 hips) partial weight-bearing $(50 \%)$ was undertaken for a mean duration of seven weeks ( 3 to 12), followed by full weight-bearing with elbow crutches or walking sticks for a mean of four weeks (2 to 12 ) before walking unaided. The quality of fixation in the acetabulum and the extent of uncovering of the acetabular component guided the decision as to the postoperative weight-bearing regime. Reoperation or revision for any reason was considered a failure. All patients with unrevised hips were invited to attend a review clinic. Prior to arrival at the clinic, patients complete an Oxford hip score (OHS) questionnaire ${ }^{19}$ which has been sent to them. The OHS measures pain and disability but not function; the best possible score is 12 and the worst is 60 . At the clinic they were examined by a clinician (DJWM, CP or JD). An anteroposterior radiograph of the pelvis, including both hips, and a cross-table horizontal beam lateral view of the resurfaced hip was taken. Radiological assessment of the acetabulum was performed using the zones of DeLee and Charnley ${ }^{20}$ and that of the femoral stem using the criteria of Amstutz et al; ${ }^{21}$ a score of 7 or more was considered significant. Thinning of the femoral neck was assessed by comparing the width of the neck on the radiographs taken at two months with the most recent films, using the femoral component as the reference for magnification. A reduction in width by at least $10 \%$ of that of the original neck was considered significant. The Brooker grading ${ }^{22}$ was used for heterotopic ossification. Survival analysis was performed using a life table and Kaplan-Meier survival plots with 95\% confidence intervals (CI).

\section{Results}

At a mean follow-up of 7.8 years (6 to 9.6) there were no cases of aseptic loosening of the acetabular component. One patient operated on at the age of 45 years died from an unrelated cause five years after the operation. Three hips $(2.7 \%)$ were converted to a THR at a mean of 3.9 years $(2$ months to 8.1 years). The Kaplan-Meier cumulative survival at nine years was $95.2 \%$ (95\% CI 89 to 100) (Fig. 7).

A total of 75 patients attended a review clinic. One could not be contacted, but his general practitioner has confirmed that he has not undergone a revision procedure, nor has he reported any hip-related pain. All the others, who were either abroad or unable to attend, returned postal questionnaire responses and had radiographs taken locally.

The median Oxford hip score in 98 patients with surviving hips at the final review was 13 and the 10th and 90th percentiles were 12 and 23, respectively. Three patients noted that the pain and disability which they recorded on the questionnaire were originating from a joint other than the resurfaced hip, such as the contralateral hip or the back.

The mean post-operative acetabular inclination was $37^{\circ}$ $\left(28^{\circ}\right.$ to $\left.49^{\circ}\right)$. There was no change in the mean acetabular inclination at follow-up. A total of 90 patients $(87.4 \%)$ had leg-length discrepancies, with a mean shortening of $9 \mathrm{~mm}$ (5 to 35) (Fig. 8).

One 50-year-old woman who had developmental dysplasia of the hip and had two childhood hip operations underwent a dysplasia BHR. Her immediate post-operative 


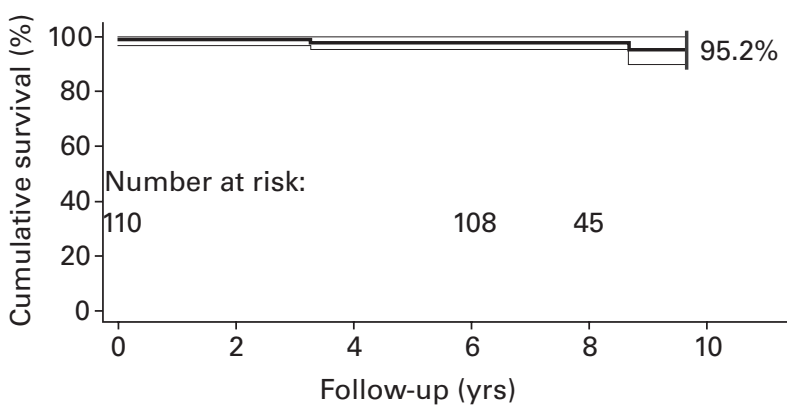

Fig. 7

Kaplan-Meier survival analysis with 95\% confidence intervals with revision for any reason as the endpoint.

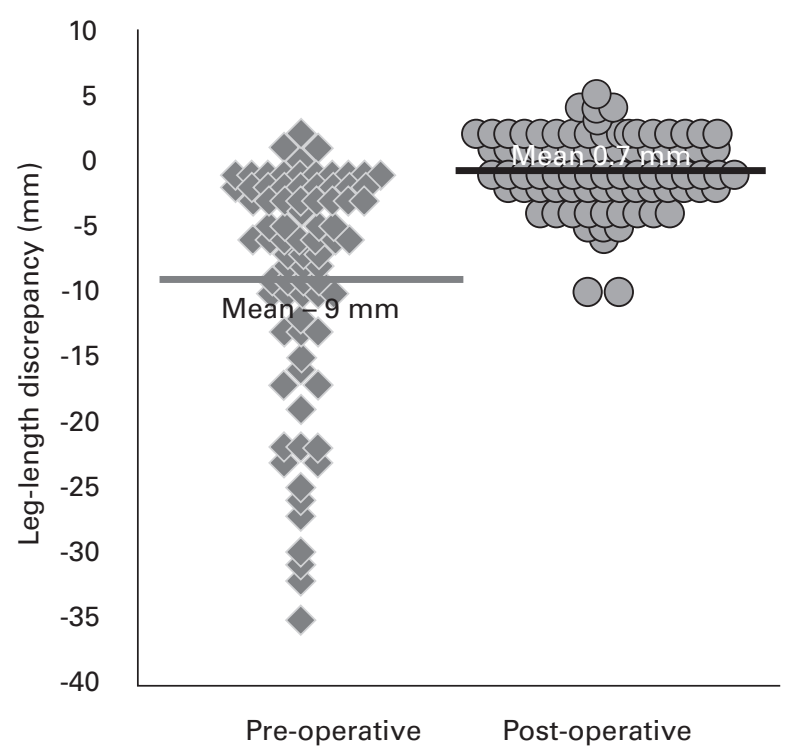

Fig. 8

Graph showing that the mean radiological leg-length discrepancy before the operation was $-9 \mathrm{~mm}$ (minus sign denotes shortening of the afected limb in unilateral cases and of the shorter limb in bilateral cases). The mean radiological discrepancy after the operation was $0.7 \mathrm{~mm}$.

radiograph showed a radiolucent line in DeLee and Charnley zones 1, 2 and 3. She had an uneventful recovery and an excellent outcome, but the lucent line has persisted in subsequent radiographs taken at one and seven years. One patient had a $2 \mathrm{~mm}$ radiolucent line around the femoral component, and five had asymptomatic thinning of the femoral neck at the latest follow-up. There was no case of osteolysis around the femoral or acetabular components and no failures due to aseptic loosening. None of the above patients is awaiting a revision.

A 43-year-old woman sustained a fracture of the femoral neck two months after her resurfacing and was revised to a THR. A 39-year-old woman failed because of deep infec- tion 3.3 years after the operation and underwent a twostage revision to a THR. A 34-year-old woman with Crowe grade III dysplasia, underwent a dysplasia BHR. She had systemic lupus erythematosus which was treated with steroids and immunosuppressants. She made a good recovery, but the femoral component underwent varus migration at six months. However, she remained asymptomatic until a fall 7.7 years later when she developed a further varus tilt of the femoral component. One year later this component was revised, because of pain, to a matching modular femoral head on a Synergy uncemented femoral component (Smith and Nephew, Memphis, Tennessee). The acetabular component was left in situ. Retrieval analysis of her femoral head showed no evidence of aseptic loosening of the femoral component or osteonecrosis but a series of microfractures, and a more extensive partial fracture with some healing. The fracture line extended centrally and was filled with fibrous tissue. These findings are consistent with early varus migration of the femoral component, which would appear to have been the result of the series of microfractures. The additional tilt she developed after the fall probably caused the partial fracture, which developed fibrous union over the next year, leading to pain on weightbearing.

A 50-year-old woman who underwent bilateral resurfacings one week apart suffered a non-fatal pulmonary embolism six weeks after the index operation. She was managed with anticoagulants and recovered fully with no sequelae. There were no cases of wound dehiscence, neurovascular injury or dislocations.

\section{Discussion}

Charnley and Feagin ${ }^{1}$ originally described untreated congenital dislocation of the hip as a contraindication to hip replacement. However, technical advances have made arthroplasty a reasonable option for severely dysplastic hips. ${ }^{23}$ As many patients with dysplasia are young, a conservative option such as hip resurfacing is reasonable.

Acetabular insufficiency in developmental dysplasia or in destructive arthritis presents as a wide spectrum of conditions with varying severity. Minor insufficiencies of the acetabulum can usually be managed by moving the acetabular component proximally or medially into a more stable location. At the other extreme, with total dislocation as in Crowe grade IV, where the true acetabulum is small, either an extremely small resurfacing femoral component would have to be used or the acetabulum would need to be overreamed. We consider both these options unacceptable and a hip resurfacing is generally not viable.

Total hip replacement with a diameter of femoral head which matches a small acetabular component is usually a more acceptable solution. In addition, although Crowe IV dislocated hips are unstable, they are not subjected to normal load-bearing stresses and are therefore less likely to become arthritic. ${ }^{24}$ By comparison, the subluxing hips seen in Crowe II and III dysplasia become painful earlier and the 
dimensions of their acetabulum and femoral head lend themselves to resurfacing. However, they may offer too little cover for the acetabular component to allow secure fixation with a standard acetabular component. Further, in the subluxing hip the femoral head articulates with the false acetabulum, leaving the acetabular roof stress shielded and relatively osteopenic, which renders it unsuitable for robust fixation with screws or cement.

With the dysplasia component used in the present study, the screws obtain purchase in the better-quality bone in the false acetabulum, providing good primary fixation. Being neutralisation screws, the acetabular component and the screws combine into one solid composite three-dimensional construct, where the stability in any plane is a function of the area circumscribed by the component and the screws as a whole. This allows the morcellised autograft filling the bony deficiency superolaterally to incorporate and consolidate without fear of displacement during weight-bearing mobilisation.

In a subluxing hip, osteopenia is often seen in the lateral aspect of the femoral head as well, and this, sometimes, is marked. We consider that one of our failures with femoral head collapse was due to osteopenia of the lateral part of the femoral head. This alerted us to this potential mode of failure early in our experience, and we have since performed THR in such patients. Patients must be warned preoperatively of the possibility of an intra-operative conversion to a THR if this localised osteopenia is found to be too severe to risk failure with a resurfacing implant.

Patients with dysplasia are often young and of childbearing age. Although current knowledge ${ }^{25}$ indicates that the placenta has a modulatory effect on metal ion transfer, it is not clear whether the raised metal ion levels have an effect on the unborn child. Metal ion levels are almost invariably elevated following a metal-on-metal hip resurfacing. ${ }^{26}$ It has therefore been our practice to advise young female patients who are planning a resurfacing and a pregnancy in the forseeable future, to have the baby before the resurfacing, or postpone it as long as possible thereafter, and in any case no less than two years after the resurfacing, in order to avoid the run-in period of high metal release.

A dysplasia component is almost always needed in a Crowe III dysplastic hip, and often in Crowe II dysplasia. Whether a hip is classified as Crowe I, II or III, the real test is the intra-operative stability afforded to the trial component by the reamed acetabulum. A standard component can be safely used if sufficient support is available for the trial component. It is not acceptable to over-ream the acetabulum in order to increase stabilisation, especially in a young patient. In marginal cases, in order to avoid using a dysplasia component there is often a tendency to implant the standard component implant in an abducted position to achieve superior cover. This must be avoided in a metal-onmetal bearing, as it leads to edge loading, accelerated wear and early failure. The defective anatomy should not be allowed to lead to compromised positioning of the acetabular component.

Amstutz, Antoniades and Le Duff ${ }^{27}$ described a series of metal-on-metal resurfacings with regular acetabular components in dysplastic hips with predominantly (88\%) Crowe I and some $(12 \%)$ Crowe II deficiencies. In their series, seven of 59 hips $(11.9 \%)$ required re-operation at a mean follow-up of six years. Of these, six hips were converted to a THR, five for femoral failure and one for recurrent subluxation. Another patient needed an acetabular reorientation after three days for instability. In comparison, the failure rate with re-operation as the endpoint in our present series is $2.7 \%$ at a mean of 7.8 years.

With the offset screws it is possible to secure the dysplasia component in a more closed position with a lower inclination angle, thereby increasing stability of the hip and reducing the chances of edge loading and wear. This option is often required to compensate for an associated increase in the valgus angle of the femoral neck, as seen from the mean inclination angle of $37^{\circ}\left(28^{\circ}\right.$ to $\left.49^{\circ}\right)$ in the present series, which was lower than the mean of $40^{\circ}$ found in a consecutive series of standard BHRs performed by the same surgeon. ${ }^{28}$ The absence of loosening and the excellent incorporation of the graft seen in our series (Figs 5 and 6) assures us of the satisfactory stability afforded by the dysplasia BHR component and the supplementary screws. It is hoped that the reconstructed bony margins of the native acetabulum will stand the patient in good stead if a revision becomes necessary. The performance of a BHR with a dysplasia component is a technically difficult procedure but the absence of loosening of the component in this series at medium-term follow-up establishes this component as a robust method of acetabular reconstruction for patients with severe acetabular insufficiency.

\section{Supplementary Material}

$\because$ A further opinion by Mr D. Dunlop is available with C the electronic version of this article on our website at www.jbjs.org.uk

The author or one or more of the authors have received or will receive benefits for personal or professional use from a commercial party related directly or indirectly to the subject of this article. In addition, benefits have been or will be directed to a research fund, foundation, educational institution, or other nonprofit organisation with which one or more of the authors are associated.

\section{References}

1. Charnley J, Feagin JA. Low friction arthroplasty in congenital subluxation of the hip. Clin Orthop 1973;91:98-113.

2. Kobayashi S, Saito N, Nawata M, et al. Total hip arthroplasty with bulk femoral head autograft for acetabular reconstruction in DDH: surgical technique. J Bone Joint Surg [Am] 2004;86-A (Suppl 1):11-17.

3. Crowe JF, Mani VJ, Ranawat CS. Total hip replacement in congenital dislocation and dysplasia of the hip. J Bone Joint Surg [Am] 1979;61-A:15-23.

4. Hartofilakidis G, Stamos K, Karachalios T, Ioannidis TT, Zacharakis N. Congenital hip disease in adults: classification of acetabular deficiencies and operative treatment with acetabuloplasty combined with total hip arthroplasty. J Bone Joint Surg [Am] 1996;78-A:683-92.

5. Anderson MJ, Harris WH. Total hip arthroplasty with insertion of the acetabular component without cement in hips with total congenital dislocation of marked congenital dysplasia. J Bone Joint Surg [Am] 1999;81-A:83-92. 
6. Dorr LD, Tawakkol S, Moorthy M, Long W, Wan Z. Medial protrusio technique for placement of a porous-coated, hemispherical acetabular component without cement in a total hip arthroplasty in patients who have acetabular dysplasia. J Bone Joint Surg [Am] 1999;81-A:83-92.

7. Schutzer SF, Harris WH. High placement of porous-coated acetabular components in complex total hip arthroplasty. J Arthroplasty 1994;9:359-67.

8. Stans AA, Pagnano MW, Shaughnessy WJ, Hanssen AD. Results of total hip arthroplasty for Crowe Type III developmental hip dysplasia. Clin Orthop 1998:348:149-57.

9. Pagnano W, Hanssen AD, Lewallen DG, Shaughnessy WJ. The effect of superior placement of the acetabular component on the rate of loosening after total hip arthroplasty. J Bone Joint Surg [Am] 1996;78-A:1004-14.

10. Gerber SD, Harris WH. Femoral head autografting to augment acetabular deficiency in patients requiring total hip replacement: a minimum five-year and an average seven-year follow-up study. J Bone Joint Surg [Am] 1986;68-A:1241-8.

11. Harris WH. Allografting in total hip arthroplasty: in adults with severe acetabular deficiency including a surgical technique for bolting the graft to the ilium. Clin Orthop 1982;162:150-64

12. Mulroy RD Jr, Harris WH. Failure of acetabular autogenous grafts in total hip arthroplasty. Increasing incidence: a follow-up note. J Bone Joint Surg [Am] 1990;72A:1536-40

13. Kobayashi S, Saito $\mathbf{N}$, Nawata $\mathbf{M}$, et al. Total hip arthroplasty with bulk femoral head autograft for acetabular reconstruction in developmental dysplasia of the hip. $J$ Bone Joint Surg [Am] 2003;85-A:615-21.

14. Mendes DG, Said M, Aslan K. Classification of adult congenital hip dysplasia for total hip arthroplasty. Orthopedics 1996;19:881-7.

15. Kerboul M, Mathieu M, Sauzieres P. Total hip replacement for congenital dislocation of the hip. In: Postel M, Kerboul M, Evrard J, Courpied JP, eds. Total hip replacement. New York: Springer, 1987:51-66.

16. Jasty M, Anderson MJ, Harris WH. Total hip replacement for developmental dysplasia of the hip. Clin Orthop 1995;311:40-5
17. Widmer KH, Zurfluh B. Compliant positioning of total hip components for optimal range of motion. J Orthop Res 2004;22:815-21.

18. Daniel J, Pynsent PB, McMinn DJ. Metal-on-metal resurfacing of the hip in patients under the age of 55 years with osteoarthritis. J Bone Joint Surg [Br] 2004;86B:177-84.

19. Dawson J, Fitzpatrick R, Carr A, Murray D. Questionnaire on the perceptions of patients about total hip replacement. J Bone Joint Surg [Br] 1996;78-B:185-90.

20. DeLee JG, Charnley J. Radiological demarcation of cemented sockets in total hip replacement. Clin Orthop 1976;121:20-32.

21. Amstutz HC, Beaulé PE, Dorey FJ, et al. Metal-on-metal hybrid surface arthroplasty: two to six-year follow-up study. J Bone Joint Surg [Am] 2004;86-A:28-39.

22. Brooker AF, Bowerman JW, Robinson RA, Riley LH Jr. Ectopic ossification following total hip replacement: incidence and a method of classification. J Bone Joint Surg [Am] 1973;55-A:1629-32.

23. Chougle A, Hemmady MV, Hodgkinson JP. Severity of hip dysplasia and loosening of the socket in cemented total hip replacement: a long-term follow-up. J Bone Joint Surg [Br] 2005;87-B:16-20.

24. Haddad FS, Masri BA, Garbuz DS, Duncan CP. Primary total replacement of the dysplastic hip. J Bone Joint Surg [Am] 1999;81-A:1462-82.

25. Ziaee H, Daniel J, Datta AK, Blunt S, McMinn DJ. Transplacental transfer of cobalt and chromium in patients with metal-on-metal hip arthroplasty: a controlled study. J Bone Joint Surg [Br] 2007;89-B:301-5.

26. Daniel J, Ziaee H, Pradham C, Pynsent P, McMinn DJ. Blood and urine metal ion studies in young and active patients with Birmingham hip resurfacings: four year results of a prospective longitudinal study. J Bone Joint Surg [Br] 2007;89-B:169-73.

27. Amstutz HC, Antoniades JT, Le Duff MJ. Results of metal-on-metal hybrid resurfacing for Crowe type-I and II developmental dysplasia. J Bone Joint Surg [Am] 2007:89-A:339-46.

28. McMinn DJ, Daniel J, Pynsent PB, Pradhan C. Mini-incision resurfacing arthroplasty of hip through the posterior approach. Clin Orthop 2005;441:91-8. 